\title{
The Roles of Individual Actors in Data-driven Service Innovation - A Dynamic Capabilities Perspective to Explore its Microfoundations
}

\author{
Martin Schymanietz \\ Friedrich-Alexander University Erlangen-Nürnberg \\ martin.schymanietz@fau.de
}

\begin{abstract}
The increasing amount of data that can be collected from interconnected devices offers various opportunities for the co-creative innovation of datadriven services. It demands for the integration of traditional and new actors that have to deal with alternating roles. Using a modified Delphi method, this study takes a microfoundational view and investigates the roles and capabilities of individual actors that together shape an organization's ability to innovate. By identifying relevant activities and their relative importance in the innovation of data-driven services, the study specifies nine actor roles and their contribution to organizational capabilities. The findings indicate that technical roles are less important than those that shape mindset and strategy. The paper contributes to current research on the utilization of data for service innovation by providing a microfoundational view of individual actors that helps to account for such higher-level phenomena as dynamic capabilities.
\end{abstract}

\section{Introduction}

Ongoing digitization and the accompanying increase in available data affects almost every aspect of industry and everyday life. This growing volume of data - from sensors, interconnected devices and associated analytics - enables organizations to improve processes and to co-create innovative datadriven service offerings that rely on data as a key resource [8]. Data-driven services are characterized by a digital nature $[61,63]$ and are sometimes used synonymously to other related concepts such as smart or digital services $[62,63]$. The core aspect of datadriven services is the utilization of data analytics for service provision [61]. Examples are services such as Rolls Royce's VisiumFUEL that allow airlines to monitor an aircraft's fuel consumption and offers

\author{
Julia M. Jonas \\ Friedrich-Alexander University Erlangen-Nürnberg \\ julia.jonas@fau.de
}

possibilities for efficiency improvements or Daimler's FleetBoard service that utilizes data from a fleet of trucks for being able to offer individualized insurance premiums [68]. The utilization of data for new types of service offerings is accompanied by a set of novel challenges such as data access and ownership, the development of new revenue and business models and deeper knowledge on customer needs [2,9]. It requires the integration of multiple actors [1-3], as services are increasingly innovated across rather than within organizations, working with customers, partners and suppliers. Within these networks, connected individual actors co-creatively integrate their resources $[3,59]$ to facilitate an organization's growth $[4,5,17]$.

To compete profitably in today's dynamic markets, organizations need to develop the requisite capabilities to reconfigure their resources, business models and organizational structures in favor of the new circumstances [7]. In so doing, they need dynamic capabilities to sense opportunities and threats, seize those opportunities, and reconfigure both tangible and intangible assets if they are to maintain or develop sustainable competitive advantage [36, p. 1319].

Understanding these high-level organizational dynamic capabilities can be achieved through a microfoundational account of the roles of individual actors [6,31,59] who shape the organization and higher-level phenomena such as dynamic capabilities $[6,31,36,60]$.

Data-driven service innovation (DDSI) provides a rich context in which to explore the nature of service innovation $[9,10]$ and the development of organizational capabilities. To illuminate value cocreation activities and their importance for DDSI, this paper takes a microfoundational view [6,31] and investigates the roles of individual actors and connected individual capabilities in that context. For this purpose, a Delphi study is carried out to investigate the roles together with practitioners. The Delphi study aims to reach consensus among a panel of experts in the field of DDSI to identify and evaluate 
individual activities, roles and the ordinary and dynamic capabilities they support.

\section{Theoretical background - Individual actors and organizational capabilities during service innovation}

During service innovation, activities, resources (e.g., physical, skills, information, knowledge) and practices are co-created or recombined through collaboration to develop solutions for new or existing problems and to deliver additional value [11-16]. Service innovation is inherently multidimensional and requires the involvement of a diverse range of actors from different organizations, units and functions. The required integration of resources cannot be carried out by a single actor and is likely to involve both external actors (e.g., customers, users, suppliers, external service providers, competitors, universities) and internal actors (e.g., top management, sales and service personnel, local subsidiaries) [17-19].

Identifying the requisite capabilities and managing multiple actors and their interaction can be complex [20], and different relationships must be established to facilitate each evolving role [21]. These roles are assigned during resource integration for value cocreation and are established through mental models, activities (such as resource exchange) and interactions with other actors [22]. Value co-creation depends on the interaction of these different actors and their joint or independent activities in enabling the exchange and integration of resources [23-26].

Especially individual actors are discussed as important during service innovation, due to the connection between individual activities and organizational outcomes [64,66]. Here, actors can have a radical or incremental influence on others and take expected or emerging roles, meaning that their roles lie in line with other actors' expectations or not [65,69]. In service innovation, individual actors may take on roles that depart from their formal (and static) position within the organization [3,23,27]. During such co-creation activities, actors may play different roles, sometimes simultaneously. The roles may change within the context of the network or in relation to other actors (that are not necessarily visible to others throughout the network). Understanding the relevance and relative importance of these roles is central to comprehending value co-creation processes among different actors [27,28].

To foster innovation capabilities, organizations must develop skills and knowledge of individual actors (e.g., thinking in systems, integrating and combining, inventive thinking, networking) [29].
Because individual actors contribute to innovative and co-creative interaction by applying their mental models [22], organizational capabilities ultimately depend on an understanding of individual capabilities [30]. This microfoundational view illuminates higherlevel phenomena such as dynamic capabilities. This view locates "the proximate causes of a phenomenon (or explanations of an outcome) at a level of analysis lower than that of the phenomenon itself" [6, p.587] and suggests that the explanation of high-level phenomena should consider lower-level ones or actors [6,31]. In a nutshell, capabilities evolve on the basis of skills, knowledge (both as used by [67]), personal characteristics, experiences, and cognitions of individual actors that - in sum - form the whole organization [31]. During value co-creation by multiple actors, understanding individual roles and connected activities (e.g., gathering knowledge and information) on a micro-level facilitates the integration of organizational assets and the development and creation of organizational capabilities [32].

In today's fast changing business environment, where the sole possession of resources alone does not guarantee sustainable competitive advantage [33], organizations must develop dynamic capabilities if they are to fully exploit their resource base $[34,35]$. Dynamic capabilities relate to doing the right things and are usually strategic. In contrast, so-called ordinary capabilities are related to operation, governance and administration of organizational activities, thus indicating if activities are carried out right [36].

During service innovation, the development of dynamic capabilities is strongly influenced by the paradigm of value co-creation [37,38]. First, new modes of interaction emerge during sensing activities. Second, opportunities are seized, shifting the focus to customer value, based on continuous co-creation activities within the service system $[37,39,40]$. Finally, the service system must be orchestrated using organizational reconfiguration capabilities $[37,38]$ and sustained by establishing a service-oriented mindset within the organization $[37,41]$.

The multidimensional nature of DDSI results in a complex process that requires the development of organizational capabilities, based on skills and knowledge of individual actors in multiple roles. To identify the requisite organizational capabilities through the examination of individual actors, their capabilities, activities and roles during the innovation of data-driven services, this paper addresses the following research question: What roles of individual actors are relevant and support the development of dynamic organizational capabilities during DDSI? 


\section{Method}

To answer the research question, we used a modified Delphi technique. Implementing the Delphi method elicits qualitative information from experts to identify relevant issues and their relative importance [42]. In a series of surveys, the technique seeks to establish a consensus within a group of experts from a given domain [43-45]. The group Delphi method allows for an interaction of participants in plenary sessions [46]. This group method preserves all other elements such as iterative feedback rounds, group judgements, and the possibility to revise opinions of a traditional Delphi study beside of anonymity [46]. The collaborative setting increases the participants' sense of responsibility and seriousness, producing results that gain higher acceptance within the group [47]. However, these plenary sessions need to be properly moderated to prevent the undue influence of dominant personalities. To that end, the moderator must seek to balance the inputs of more and less communicative panelists [46].

To identify individual actor roles contributing to DDSI, we invited 22 professionals with experience in that context (see Table 1).

Table 1. Overview of panelists

\begin{tabular}{|c|c|c|}
\hline \# & Position & Industry \\
\hline 1 & Deputy General Manager & Manufacturing \\
\hline 2 & $\begin{array}{l}\text { Digital Transformation } \\
\text { Program Manager }\end{array}$ & Finance \\
\hline 3 & Director & Technology \\
\hline 4 & Lead Product Manager & IT \\
\hline 5 & Technology Director & IT \\
\hline 6 & $\begin{array}{c}\text { Partner Development } \\
\text { Manager }\end{array}$ & IT \\
\hline 7 & $\begin{array}{c}\text { Business Transformation } \\
\text { Head }\end{array}$ & IT \\
\hline 8 & General Manager & Telecommunication \\
\hline 9 & General Manager & Engineering \\
\hline 10 & $\begin{array}{l}\text { Director Digital } \\
\text { Transformation }\end{array}$ & Technology \\
\hline 11 & Chief Product Owner & Manufacturing \\
\hline 12 & Head of Sales & IT \\
\hline 13 & Program Manager & Engineering \\
\hline 14 & Lead Portfolio Manager & IT \\
\hline 15 & Senior Expert ICT & Telecommunication \\
\hline 16 & Senior Director & IT \\
\hline 17 & Senior Director & IT \\
\hline 18 & CEO & Logistics \\
\hline 19 & Lead Project Manager & Engineering \\
\hline 20 & Process Architect & Engineering \\
\hline 21 & Partner Manager & IT \\
\hline 22 & $\begin{array}{c}\text { Regional Business } \\
\text { Development Manager }\end{array}$ & Telecommunication \\
\hline
\end{tabular}

To ensure sufficient knowledge about the phenomenon under investigation, the main selection criteria included a leadership position within their organization. All of these experts have deep knowledge of the DDSI process within their affiliated organization. To avoid cultural bias and to ensure a range of perspectives on the phenomenon in question, the selected international panelists were from different industries and varied backgrounds [46,48].

The modified Delphi method was used to rank issues to develop a consensus [42] through group interaction among the selected experts [46]. The first round explored the activities performed during DDSI. In the second round, the experts were asked to prioritize key activities, which were then ranked in a final third round (see Figure 1).

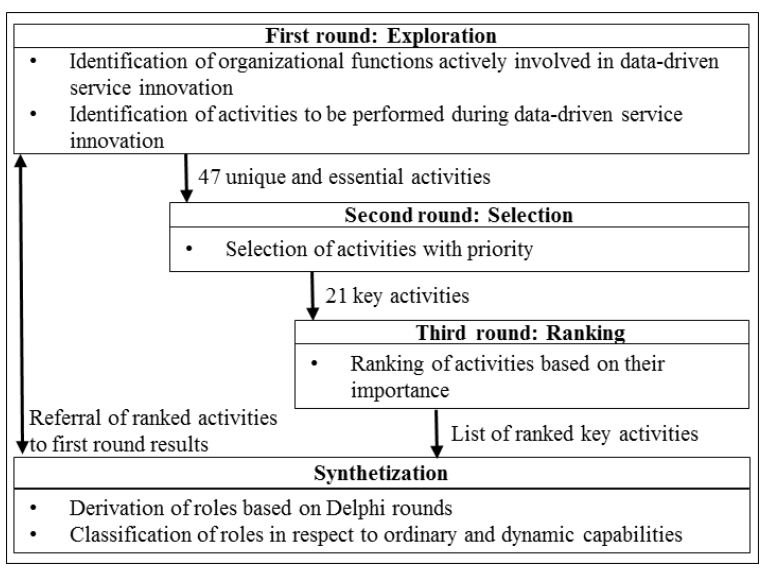

Figure 1. Implemented Delphi method $[42,46]$

To capture the activities performed during DDSI, an abductive approach was used to derive categories from the ground up as they emerged from the data analysis [49]. First, the activities mentioned by the panelists were coded descriptively, summarized in a short sentence or descriptive word. In a first overview of emerging topics, these descriptive codes formed the basis for further coding, analysis and interpretation [50,51]. In a second cycle, pattern coding was used to reduce the number of descriptive codes. Pattern codes are "explanatory or inferential codes, ones that identify an emergent theme, configuration, or explanation" [52, p. 86], synthesizing major themes into smaller sets of commonalities [50,52].

\section{Findings}

\subsection{First Delphi round - Exploration of functions and activities}


During the first round of the Delphi study, the panelists were asked about their understanding of what a data-driven service is. They were questioned to identify the actors that are actively involved in DDSI and the activities they perform. The initial questionnaire presented a range of organizational functions and external actors, as well as an open-ended option to identify other activities and free text fields for expressing further personal views without restriction. The initial results (summarized in Table 2) show that a majority of participants identified innovation management, $\mathrm{R} \& \mathrm{D}$, customers, general management and the internal IT department as playing an active role during DDSI. As $86 \%(19 / 22)$ of the panelists assumed that most activities could be handled internally, external actors such as universities and research partners received relatively few mentions.

Table 2. Organizational functions and external actors in DDSI

\begin{tabular}{|c|c|c|}
\hline Rank & Function & Total / \% \\
\hline 1 & Innovation management & $16 / 73 \%$ \\
\hline 2 & R\&D department & $14 / 64 \%$ \\
\hline 3 & Customers & $13 / 59 \%$ \\
\hline 4 & Management & $12 / 55 \%$ \\
\hline 5 & Internal IT department & $11 / 50 \%$ \\
\hline 6 & Marketing department & $9 / 41 \%$ \\
\hline 7 & Product management & $9 / 41 \%$ \\
\hline 8 & Service department & $9 / 41 \%$ \\
\hline 9 & Engineering department & $6 / 27 \%$ \\
\hline 10 & Purchasing department & $5 / 23 \%$ \\
\hline 11 & Sales department & $5 / 23 \%$ \\
\hline 12 & Universities \& research partners & $5 / 23 \%$ \\
\hline 13 & External data service providers & $3 / 14 \%$ \\
\hline 14 & Legal department & $3 / 14 \%$ \\
\hline
\end{tabular}

Additionally, the panelists referred to 47 essential and unique activities that need to be performed during DDSI. These activities were coded (as described earlier) and assigned to the following four categories.

(1) Managerial. The first category of activities includes decisions about market launches, risk and impact analyses, different areas of management across the organization, research on customer needs, and ecosystem analysis.

(2) Processes \& Methods. This category includes enablement of internal interactions, planning for innovation, formulation of business rules, and design thinking, piloting, and prototyping.

(3) Culture \& Mindset. This category includes promotion of lean thinking, ensuring team members' freedom, promoting continuous innovation, and promoting mindset change. Although linked to the first category, these activities are strategic in nature, differentiating them from managerial concerns.

(4) Technical. This category includes application of artificial intelligence (AI), machine learning, and data analytics or blockchain, as well as provision of knowledge in relation to technology, data architectures, chatbots, and domain-specific applications.

\subsection{Second Delphi round - Identification of key activities}

In the second Delphi round, the participants were asked to identify a reduced set of essential activities for DDSI. At the beginning of this round, examples of data-driven services were presented to the participants to gain a common understanding in the group and to enable the participants to revise previous statements on their understanding. Afterwards, the first round results were presented to the panelists and were brought up for discussion as well. The panelists extended the existing set of activities (see Figure 2) to include the following:

\begin{tabular}{|c|c|}
\hline $\begin{array}{l}\text { (1) Managerial } \\
\text { - Manage products \& } \\
\text { services } \\
\text { - Decide on market launch } \\
\text { - Prioritize activities } \\
\text { - Analyze value of solution } \\
\text { - Ansure funding } \\
\text { - Analyze risks } \\
\text { - } \text { Forecasting } \\
\text { - Motivate employees } \\
\text { - Break structures } \\
\text { - Research customer needs } \\
\text { - Understand customers } \\
\text { - Analyze customers } \\
\text { - Integrate customers } \\
\text { - Gain ecosystem knowledge } \\
\text { - Leadership support } \\
\text { Capability assessment }\end{array}$ & $\begin{array}{l}\text { (2) Processes \& Methods } \\
\text { - Plan innovation } \\
\text { - Enable internal interaction } \\
\text { - Remove organizational } \\
\text { obstacles } \\
\text { - Integrate internal actors } \\
\text { - Undestand internal } \\
\text { - } \text { processes } \\
\text { - Ereate business rules } \\
\text { - Estable feedback loops } \\
\text { - lifecycle } \\
\text { - Establish process for DDSI } \\
\text { - Use service design methods } \\
\text { - Use prototyping } \\
\text { - Ese piloting } \\
\text { - Prable sandboxing }\end{array}$ \\
\hline $\begin{array}{l}\text { (3) Culture \& Mindset } \\
\text { - Think lean } \\
\text { - Challenge current tasks } \\
\text { - Decentralize control } \\
\text { - Ensure freedom } \\
\text { - Be adaptable } \\
\text { - Promote constant } \\
\text { innovation } \\
\text { - Think lateral } \\
\text { - Think out of the box } \\
\text { - Think visionary } \\
\text { - Promote mindset change } \\
\text { - Failure culture }\end{array}$ & $\begin{array}{l}\text { (4) Technical } \\
\text { - Apply AI } \\
\text { - Apply Blockchain } \\
\text { - Apply data analytics } \\
\text { - Apply data mining } \\
\text { - Provide knowledge on } \\
\text { technologies } \\
\text { - Provide data architecture } \\
\text { knowledge } \\
\text { - Provide chatbot knowledge } \\
\text { Provide domain application } \\
\text { knowledge }\end{array}$ \\
\hline
\end{tabular}

\section{Figure 2. Categories and activities}

leadership support and capability assessment (both to be added to the managerial category), process evaluation methods (processes and methods category), 
and failure culture (culture and mindset category). This process yielded a total of 51 unique activities.

Participants were then asked to select five priority activities from each of the four categories. This yielded a total of 21 activities, three of which tied for fourth place in the Culture \& Mindset category and were therefore progressed to the next round. After discussing the results, the panel made no changes to the 21 selected activities.

\subsection{Third Delphi round - Ranking of activities by importance}

Finally, the remaining panelists were asked to rank these 21 activities in order of importance. Table 3 reports these rankings, including average rank and inclusion in the top ten.

Table 3. Overview of activities and final rankings

\begin{tabular}{|c|c|c|c|c|}
\hline Rank & Activity & Cat. & $\begin{array}{l}\text { Avg. } \\
\text { Rank }\end{array}$ & $\begin{array}{l}\text { Ranked } \\
\text { in top } \\
10 \text { by }\end{array}$ \\
\hline 1 & Leadership support & (1) & 4.2 & $82.0 \%$ \\
\hline 2 & Understand customers & (1) & 4.7 & $90.9 \%$ \\
\hline 3 & $\begin{array}{l}\text { Remove organizational } \\
\text { obstacles }\end{array}$ & (2) & 6.4 & $82.0 \%$ \\
\hline 4 & $\begin{array}{l}\text { Provide insights on } \\
\text { customers }\end{array}$ & (1) & 7.3 & $63.6 \%$ \\
\hline 5 & Failure culture & (3) & 7.4 & $81.8 \%$ \\
\hline 6 & Support prototyping & $(2)$ & 8.2 & $72.7 \%$ \\
\hline 7 & $\begin{array}{l}\text { Establish process for } \\
\text { DDSI }\end{array}$ & (2) & 8.9 & $72.7 \%$ \\
\hline 8 & Think visionary & (3) & 9.0 & $63.6 \%$ \\
\hline 9 & Enable feedback loops & $(2)$ & 9.7 & $72.7 \%$ \\
\hline 10 & Decentralize control & (3) & 10.1 & $63.6 \%$ \\
\hline 11 & Promote mindset change & (3) & 10.5 & $45.5 \%$ \\
\hline 12 & Analyze value of solution & $(1)$ & 10.9 & $54.5 \%$ \\
\hline 13 & $\begin{array}{l}\text { Ensure freedom/Think out } \\
\text { of the box }\end{array}$ & (3) & 11.1 & $45.5 \%$ \\
\hline 14 & $\begin{array}{l}\text { Decide on market launch } \\
\text { strategy }\end{array}$ & (1) & 12.4 & $36.4 \%$ \\
\hline 15 & $\begin{array}{l}\text { Promote constant } \\
\text { innovation }\end{array}$ & (3) & 13.5 & $36.4 \%$ \\
\hline 16 & $\begin{array}{l}\text { Establish innovation } \\
\text { lifecycle }\end{array}$ & (2) & 14.7 & $27.3 \%$ \\
\hline 17 & Machine learning & $(4)$ & 15.3 & $0.0 \%$ \\
\hline 18 & Data analytics & $(4)$ & 15.7 & $0.0 \%$ \\
\hline 19 & $\begin{array}{l}\text { Domain-specific } \\
\text { application }\end{array}$ & (4) & 16.2 & $9.1 \%$ \\
\hline 20 & Data architecture & (4) & 17.1 & $0.0 \%$ \\
\hline 21 & AI & $(4)$ & 17.7 & $0.0 \%$ \\
\hline
\end{tabular}

In this third round, only 11 of the 20 second round panelists responded. This low response rate and the panelists' reluctance to change their opinions indicated that further rounds would not be meaningful.
The third round results show that the panelists prioritized managerial activities such as leadership support and understanding customers. These are followed by activities such as removing organizational obstacles, providing insights on customers, and creating a failure culture, as well as processual and methodological activities like the support of prototyping and establishing a process for DDSI. Although many technical activities were mentioned as important and discussed during the initial rounds, these occupied the five lowest positions here. Top ten activities were ranked as such by at least $64 \%$ of the panelists, and technical activities were almost completely absent. Among technical activities, only domain-specific application gained a mention in the top ten (ranked $6^{\text {th }}$ by a single panelist) while the rest completely failed to reach high rankings.

The strength of the group consensus was assessed by the calculation of Kendall's coefficient of concordance (W) [42]. Kendall's W is a nonparametric indicator; a value of 0 can be interpreted as complete absence of consensus within a group while a value of 1 indicates perfect consensus [43]. In the present case, a value of 0.41 for Kendall's W indicated weak to moderate group consensus on all activities. However, the top five activities achieved strong consensus, with a value of 0.73 .

\subsection{Synthetization of results}

By synthetizing these results, it was possible to characterize actors' roles in DDSI. In particular, the prioritized activities from the third round were referred back to the activities and descriptive codes initially mentioned during the first Delphi round. This means that the roles were derived based on the statements from the panelists from all three Delphi rounds. For example, the description of the customer expert role does not only base on the derived code "Understand customers", but also on these exemplary statements of the panelists from the first round such as the necessity of "a constant interaction with customers for reactive feedback for iterations" or a "good understanding of customers' problems and at what point in the journey" that were coded to the activities from figure 2 .

This yielded nine distinct roles describing the activities of individual actors.

(1) The customer expert provides deep knowledge of the customer and his needs throughout the DDSI process, based on research activities and direct and continuous interaction with the customer.

(2) The supporting manager ensures top management support for establishing a failure culture and the freedom of other actors to unleash their creativity and think "out of the box." 
(3) The innovation enabler establishes processes that balance product and service innovation and promotes the constant pursuit of innovation to ensure adaptability throughout an appropriate lifecycle.

(4) The bridge builder contributes a deep understanding of the organizational environment and removes any obstacles that might prevent collaboration at intra- and inter-organizational level.

(5) The prototyper establishes and implements prototyping methods to assess the feasibility of the innovated solution(s), enabling iterative feedback loops and setting suitable timeframes for prototyping.

(6) The strategic operationalizer puts the innovation into action, decides how solutions are advanced to the next process step and devises market launch strategy.

(7) The mindset visionary identifies current market trends for vision delivery and promotes mindset change to facilitate innovation of data-driven services.

(8) The technical expert provides the required technical knowledge on artificial intelligence, machine learning and other technologies across the entire process of DDSI and assesses the technical feasibility of the new solution(s).

(9) The t-shaped expert links the insights delivered by the technical expert to domain-specific applications to ensure correct data interpretation for appropriate solutions that offer additional value to the customer.

As a next step, these roles were classified as supporting the development of ordinary or dynamic capabilities. In the latter case, actor roles related to sensing, seizing and transforming capabilities for service innovation (see Figure 3). The technical and $t$ shaped expert roles support ordinary capabilities. The technical expert provides knowledge on IT-related technologies, and the t-shaped expert connects these to domain-specific knowledge. Both roles are highly operational and can be outsourced to external service providers rather than residing within the organization.

Roles that support the development of dynamic capabilities can be characterized as follows. The customer expert senses new opportunities in the market through direct interaction with the customer and research on their needs. In seizing identified opportunities, the bridge builder, prototyper, and strategic operationalizer support dynamic capability development by dismantling organizational barriers to facilitate reconfiguration of existing resources, parallel prototyping of multiple solutions, and timely market introduction. The supporting manager and the innovation enabler can be assigned to a dual role of seizing and reconfiguring. They provide the freedom and structures to seize opportunities and reconfigure the organization by implementing a new culture of ongoing innovation that encourages employees to try new things. Finally, the mindset visionary is mainly responsible for reconfiguring the organization by defining a vision for the whole organization, shaping the future mindset and supporting the realignment of organizational assets to ensure sustainable competitive advantage.

\begin{tabular}{|c|c|c|c|}
\hline \multicolumn{4}{|c|}{ Roles supporting the development of dynamic capabilities } \\
\hline Sensing & \multicolumn{2}{|c|}{ Seizing } & Transforming \\
\hline $\begin{array}{c}\text { (1) The customer } \\
\text { expert }\end{array}$ & \multicolumn{3}{|c|}{ (2) The supporting manager } \\
\hline & \multicolumn{3}{|c|}{ (3) The innovation enabler } \\
\hline & \multicolumn{2}{|c|}{$\begin{array}{l}\text { (4) The bridge } \\
\text { builder }\end{array}$} & $\begin{array}{l}\text { (7) The mindset } \\
\text { visionary }\end{array}$ \\
\hline & \multicolumn{2}{|c|}{$\begin{array}{l}\text { (5) The } \\
\text { prototyper }\end{array}$} & \\
\hline & \multicolumn{2}{|c|}{$\begin{array}{l}\text { (6) The strategic } \\
\text { operationalizer }\end{array}$} & \\
\hline \multicolumn{4}{|c|}{ Roles supporting the development of ordinary capabilities } \\
\hline \multicolumn{2}{|c|}{ (8) The technical expert } & \multicolumn{2}{|c|}{ (9) The t-shaped expert } \\
\hline
\end{tabular}

Figure 3. Roles supporting ordinary and dynamic capabilities

\section{Discussion}

This study sheds light on individual actors, roles, and activities involved in DDSI in relation to traditional functions. The findings indicate a strong focus on managerial activities rather than technical knowledge. Synthetization revealed nine actor roles and associated ordinary and dynamic organizational capabilities.

The study at hand extends existing research on actor roles during co-creative DDSI [23,24,26] by identifying roles of actors at a micro-level and connecting these to the higher-level phenomenon of dynamic capabilities [31,32]. The present findings consolidate earlier evidence that actors from internal departments such as innovation management, R\&D, management and IT, as well as customers, play a vital role in successful innovation of data-driven services $[17,18]$. The findings emphasize roles that do not align completely with organizational functions or their assumed importance. For instance, the roles deemed most important relate to facilitating leadership support for a culture that allows for failure and fully exploits knowledge of customer needs and their understanding. Formal organizational functions such as management and sales were considered less important than the activities they perform in the context of DDSI - in other words, co-creative actors' roles in DDSI are characterized by the specific activities they perform 
rather than by their formal organizational designation [23].

This emphasis on roles rather than formal organizational functions reflects how dynamic environments require actors to change their role to facilitate fruitful co-creation activities such as DDSI $[27,53]$. The roles described here are not executed by single actors alone, and individual actors can perform multiple roles as their environment changes [23]. For example, the roles of supporting manager and mindset visionary can (but need not) be performed by one actor.

The relevance of actor roles that support sensing, seizing and reconfiguration capabilities serves to clarify how organizations can achieve sustainable competitive advantage through dynamic capability development [54]. In particular, the importance of strategic and managerial activities that shape the organizational mindset and culture shows that successful DDSI relies heavily on the development of dynamic capabilities. This is supported by the perceived lesser importance of technical activities such as application of AI, data analytics, machine learning, or domain-specific knowledge. As ordinary capabilities that are imitable and cannot ensure sustainable competitive advantage, these operational functions can readily be outsourced to external service providers [36].

The lesser importance of technology in exploiting new service opportunities serves as a reminder that DDSI presents partially the same challenges as service innovation in general. However, they are gaining in complexity through the utilization of data. As long as organizations do not promote a service-oriented mindset through top management [55,56] and establish suitable internal processes for service innovation [57,58], an engagement with mainly DDSI related challenges can be impeded. In such cases, the deeper focus on technological issues becomes more difficult, as does the development of appropriate dynamic capabilities that are relatively inimitable [36].

Roles such as the technical or t-shaped expert could be furthermore regarded as ordinary due to their incremental and expected nature. Both of them just provide knowledge on an operational level. In contrast, roles that support dynamic capability development show characteristics of being more emerging and radical $[65,67]$. This can be exemplified by the mindset visionary that has the ability to act radical and emerging due to his role to deliver visions, by the customer expert that can act unexpectedly on novel demands from customers or the strategic operationalizer that creates his role throughout DDSI which has not to be in line with the expectations of others. An explanation for the underrepresentation of roles that support sensing activities could be that the customer acts as an active innovator during DDSI, thus lowering the demand for further sensing capabilities beside of the customer expert. Finally, the study's findings confirm the importance of integrating actors and micro-level activities in order to develop higherlevel dynamic capabilities [6,31] for innovation of data-driven services. Concrete description of individual roles and activities to support the development of such capabilities [6,31,32] helps to achieve sustainable competitive advantage by doing the right things rather than just doing things right [36]. The identified roles can help to support organizational outcomes through individual activities [6] and their contribution towards DDSI [64]

\section{Conclusion and outlook}

In summary, this study identifies the roles of individual actors in DDSI and the capabilities required, specifying their relative importance as perceived by a panel of selected experts. The paper identifies nine roles and links these to the dynamic capabilities framework to show how micro-level activities help to build higher-level dynamic organizational capabilities within organizations. This study shows that actor roles during DDSI can support both ordinary and dynamic capability development. While roles incorporating technical knowledge and their domain specific application have the potential to be outsourced to external service providers due to their lower perceived importance, strategic and managerial roles that shape an organizations mindset support the development of dynamic capabilities. The paper emphasizes that multiple roles can be taken by single actors and that the identified roles go beyond static and formal organizational roles that were perceived less important than the activities they perform.

From a managerial perspective, the findings help organizations to define the roles and activities of those involved in DDSI. By developing these dynamic capabilities, managers can build competitive advantage through data-driven services. This implies that teams for DDSI should be constructed on the basis of these roles and activities rather than adhering to formal and often static organizational roles.

Beyond these timely contributions, this Delphi study has certain limitations that need to be considered. In particular, the composition of the expert panel limits the representativeness of the findings. Although diverse in terms of industry and background, the participants provide only an internal perspective on data-driven service providers and not the customer perspective. Furthermore, the expert panel com- 
position does not only limit the representativeness of the findings, but also effects the findings of the study. A more heterogeneous composition might have led to other roles. Different cultural context and diverse educational background might have resulted in different activities and roles for DDSI.

The study opens up some interesting avenues for future research in the developing field of DDSI. First, the identified actor roles and capabilities should be investigated and refined, using a combination of qualitative and quantitative methods to validate our findings. Additional insights from in-depth exploration of the capabilities that organizations have built would help to advance our understanding of how dynamic capabilities build competitive advantage in rapidly changing environments.

Beyond the insider view, future research could explore the whole ecosystem around providers of datadriven services. This may reveal additional roles of relevance to DDSI, encompassing external actors such as customers, suppliers, and research partners or others and assess if they are needed to innovate data-driven services. Furthermore, future research could investigate specific data utilization triggered aspects rather than taking a broad view on the phenomenon of DDSI as in the present study.

Finally, future studies may investigate the surprising finding that technical aspects are assigned relatively low priority. It would be interesting, for example, to determine whether this rests on an assumption that technical issues can be more easily mastered during data-driven services innovation or whether it reflects deficiencies in dynamic capabilities for organizational transformation.

\section{Acknowledgements}

We would like to thank the panelists, and Prof. Dr. Kathrin Möslein for her valuable comments and suggestions for developing this study. The research presented in this study was partially funded by the German Federal Ministry of Education and Research in course of the project BigDieMo, FKZ 02K14A121.

\section{References}

[1] N. Stein, J. Meller, and C.M. Flath, "Big data on the shop-floor: sensor-based decision-support for manual processes", Journal of Business Economics, 88 (5), 2018, pp. 593-616.

[2] M. Porter and J. Heppelmann, "How Smart, Connected Products Are Transforming Competition”, Harvard Business Review, November 2014. https://hbr.org/2014/11/howsmart-connected-products-are-transforming-competition.
[3] R. Lusch and S. Nambisan, "Service Innovation: A Service-Dominant-Logic perspective", MIS Quarterly, 39 (1), 2015, pp. 155-175.

[4] A. Ordanini and A. Parasuraman, "Service Innovation Viewed Through a Service-Dominant Logic Lens: A Conceptual Framework and Empirical Analysis", Journal of Service Research, 14 (1), 2011, pp. 3-23.

[5] M. Barrett, E. Davidson, J. Prabhu, and S.L. Vargo, "Service Innovation in the Digital Age: Key Contributions and Future Directions", MIS Quarterly, 39 (1), 2015, pp. $135-154$

[6] T. Felin, N.J. Foss, and R.E. Ployhart, "The Microfoundations Movement in Strategy and Organization Theory", The Academy of Management Annals, 9(1), 2015, pp. 575-632.

[7] D.J. Teece, "Profiting from innovation in the digital economy: Enabling technologies, standards, and licensing models in the wireless world", Research Policy, 47 (8), 2018, pp. 1367-1387.

[8] P.M. Hartmann, M. Zaki, N. Feldmann, and A. Neely, "Capturing value from big data - A taxonomy of data-driven business models used by start-up firms", International Journal of Operations \& Production Management, 36 (10), 2016, pp. 1382-1406.

[9] R. Schüritz, S. Seebacher, and R. Dorner, "Capturing value from data: Revenue models for data-driven services", In: Proceedings of the $50^{\text {th }}$ Hawaii International Conference on System Sciences (HICSS), 2017, pp. 5348-5357.

[10] S. Lenka, V. Parida, and, J. Wincent, J., "Digitalization Capabilities as Enablers of Value Co-Creation in Servitizing Firms", Psychology \& Marketing, 34 (1), 2017, pp. 92-100.

[11] S.L. Vargo, H. Wieland, and M.A. Akaka, "Innovation through institutionalization: A service ecosystems perspective", Industrial Marketing Management, 44, 2015, pp. 63-72.

[12] K. Koskela-Huotari, B. Edvardsson, J.M. Jonas, D. Sörhammar, and L. Witell, "Innovation in service ecosystems - Breaking, making, and maintaining institutionalized rules of resource integration", Journal of Business Research, 69 (8), 2016, pp. 2964-2971.

[13] R.F. Lusch, and S.L. Vargo, "Service-Dominant Logic: Premises, Perspectives, Possibilities", Cambridge University Press, Cambridge, UK, 2014.

[15] T. Böhmann, J.M. Leimeister, and K.M. Möslein, "Service Systems Engineering", Business \& Information Systems Engineering, 6 (2), 2014, pp. 73-79.

[16] T. Tuunanen, A. Bask, and H. Merisalo-Rantanen, "Typology for Modular Service Design", International 
Journal of Service Science, Management, Engineering, and Technology, 3 (3), 2012, pp. 99-112.

[17] D. Kindström, C. Kowalkowski, and T. Alejandro, "Adding services to product-based portfolios", Journal of Service Management, 26 (3), 2015, pp. 372-393.

[18] J.M. Jonas, A. Roth, and K.M. Möslein, "Stakeholder Integration for Service Innovation in German Medium-Sized Enterprises", Service Science, 8 (3), 2016, pp. 320-332.

[19] J.B. Goes, and S.H. Park (1997), "Interorganizational Links and Innovation: The Case of Hospital Services", The Academy of Management Journal, 40 (3), 1997, pp. 673696.

[20] K. Kazadi, A. Lievens, and D. Mahr, "Stakeholder cocreation during the innovation process: Identifying capabilities for knowledge creation among multiple stakeholders", Journal of Business Research, 69 (2), 2015, pp. 525-540.

[21] V.M. Story, C. Raddats, J. Burton, J. Zolkiewski, and T. Baines, "Capabilities for advanced services: A multi-actor perspective", Industrial Marketing Management, 60, 2017, pp. 54-68.

[22] B. Tronvoll, "The Actor: The Key Determinator in Service Ecosystems”, Systems, 5(2), 2017, pp. 1-14.

[23] C.F. Breidbach, and P.P. Maglio, "Technology-enabled value co-creation: An empirical analysis of actors, resources, and practices", Industrial Marketing Management, 56, 2016, pp. $73-85$.

[24] K. Storbacka, R.J. Brodie, T. Böhmann, P.P. Maglio, and S. Nenonen, "Actor engagement as a microfoundation for value co-creation", Journal of Business Research, 69 (8), 2016, pp. 3008-3017.

[25] C. Peters, P.P. Maglio, R. Badinelli, R.R. Harmon, R. Maull, J.C. Spohrer, T. Tuunanen, S.L. Vargo, J.J. Welser, H. Demirkan, T.L. Griffith, and Y. Moghaddam, "Emerging Digital Frontiers for Service Innovation", Communications of the Association for Information Systems, 39 (1), 2016, pp. 136-149.

[26] L. Aarikka-Stenroos, and E. Jaakkola, "Value cocreation in knowledge intensive business services: A dyadic perspective on the joint problem solving process", Industrial Marketing Management, 41 (1), 2012, pp. 15-26.

[27] P. Ekman, R.D. Raggio, and S.M. Thompson, "Service network value co-creation: Defining the roles of the generic actor", Industrial Marketing Management, 56, 2016, pp. 5162.

[28] J.D. Chandler, and R.F. Lusch, "Service systems: A broadened framework and re- search agenda on value propositions, engagement, and service experience", Journal of Service Research, 18 (1), 2015, pp. 6-22.
[29] J.A.G. van Kleef, and N.J. Roome, "Developing capabilities and competence for sustainable business management as innovation: a research agenda", Journal of Cleaner Production, 15, 2007, pp. 38-51.

[30] T. Felin, and W.S. Hesterly, "The knowledge-based view, nested heterogeneity, and new value creation: philosophical considerations on the locus of knowledge", Academy of Management Review, 32, 2007, pp. 195-218.

[31] T. Felin, N.J. Foss, K.H. Heimeriks, and T.L. Madsen, "Microfoundations of Routines and Capabilities: Individuals, Processes, and Structure", Journal of Management Studies, 49, 2012, pp. 1351-1374.

[32] L. Argote, and Y. Ren, "Transactive Memory Systems", Journal of Management Studies, 49, 2012, pp. 1375-1382.

[33] D. Opresnik, and M. Taisch. "The value of Big Data in servitization", International Journal of Production Economics, 165, 2015, pp. 174-184.

[34] D. J. Teece, G. Pisano, and A. Shuen, "Dynamic capabilities and strategic management", Strategic Management Journal, 18 (7), 2007, pp. 509-533.

[35] K.M. Eisenhardt, and J.A. Martin, "Dynamic capabilities: what are they?", Strategic Management Journal, 21 (10-11), 2000, pp. 1105-1121.

[36] D.J. Teece, "Towards a capability theory of (innovating) firms: implications for management and policy”, Cambridge Journal of Economics, 41 (3), 2017, pp. 693-720.

[37] D. Kindström, C. Kowalkowski, and E. Sandberg, "Enabling service innovation: A dynamic capabilities approach", Journal of Business Research, 66 (8), 2013, pp. 1063-1073.

[38] P. den Hertog, W. van der Aa, and M.W. de Jong, „Capabilities for managing service innovation: towards a conceptual framework", Journal of Service Management, 21 (4), 2010, pp. 490-514.

[39] I. Alam. "Removing the fuzziness from the fuzzy frontend of service innovations through customer interactions", Industrial Marketing Management, 35 (4), 2006, pp. 468480.

[40] J. Sundbo, "Management of innovation in services", Service Industries Journal, 17 (3), 1997, pp. 432-455.

[41] P. Matthyssens, K. Vandenbempt, and L. Berghman, "Value innovation in business markets: Breaking the industry recipe", Industrial Marketing Management, 35 (6), 2006, pp. 751-761.

[42] R.C. Schmidt, "Managing Delphi Surveys Using Nonparametric Statistical Techniques", Decision Sciences, 28 (3), 1997, pp. 763-774. 
[43] C. Okoli, and S.D. Pawlowski, "The Delphi method as a research tool: An example, design considerations and applications", Information and Management, 42 (1), 2004, pp. 15-29.

[44] N. Dalkey, O. Helmer, "An experimental application of the Delphi method to the use of experts", Management Science 9 (3), 1963, pp. 458-467.

[45] H.A. Linstone and M. Turoff, "The Delphi Method: Techniques and Applications", Addison-Wesley, London, 1975.

[46] T. Webler, D. Levine, H. Rakel, and O. Renn, "A novel approach to reducing uncertainty: The group Delphi", Technological Forecasting and Social Change, 39 (3), 1991, pp. 253-263.

[47] J. Landeta,, J. Barrutia, and A. Lertxundi, "Hybrid Delphi: A methodology to facilitate contribution from experts in professional contexts", Technological Forecasting \& Social Change, 78 (9), 2011, pp. 1629-1641.

[48] K.Q. Hill, and J. Fowles, "The Methodological Worth of the Delphi Forecasting Technique", Technological Forecasting and Social Change, 7, 1975, pp. 179-192.

[49] A. Van de Ven, "Engaged scholarship: a guide for organizational and social research: A guide for organizational and social research", Oxford University Press, Oxford, UK, 2007.

[50] J. Saldaña, "The coding manual for qualitative researchers", Sage, London, 2016.

[51] H. Wolcott, "Transforming Qualitative Data Description, Analysis, and Interpretation", Sage, Thousand Oaks, CA, 1994.

[52] M.B. Miles, M.A. Huberman, and J. Saldaña, "Qualitative data analysis: A methods sourcebook", Sage Publications, Los Angeles, CA, 2013.

[53] B. Edvardsson, B. Tronvoll, and T. Gruber, "Expanding understanding of service exchange and value co-creation: a social construction approach", Journal of the Academy of Marketing Science, 39 (2), 2011, pp. 327-339.

[54] D.J. Teece, "Explicating dynamic capabilities: the nature and microfoundations of (sustainable) enterprise performance", Strategic Management Journal, 28 (13), 2007, pp. 1319-1350.

[55] R. Oliva, and R. Kallenberg, „Managing the transition from products to services", International Journal of Service Industry Management, 14 (2), 2003, pp. 160-172.

[56] H. Gebauer, E. Fleisch, and T. Friedli, "Overcoming the Service Paradox in Manufacturing Companies", European Management Journal, 23 (1), 2005, pp. 14-26.
[57] A. Neely, "Exploring the financial consequences of the servitization of manufacturing", Operations Management Research, 1 (2), 2008, pp. 103-118.

[58] V. Martinez, M. Bastl, J. Kingston, and S. Evans, "Challenges in transforming manufacturing organisations into product-service providers", Journal of Manufacturing Technology Management, 21 (4), 2010, pp.449-469.

[59] F.T. Rothaermel, and A.M. Hess, "Building Dynamic Capabilities: Innovation Driven by Individual-, Firm-, and Network-Level Effects", Organization Science, 18(6), 2007, pp. 898-921.

[60] C. Salvato, "Capabilities Unveiled: The Role of Ordinary Activities in the Evolution of Product Development Processes", Organization Science, 20(2), 2009, pp. 384-409.

[61] R. Schüritz, S. Seebacher, G. Satzger, and L. Schwarz, "Datatization as the Next Frontier of Servitization Understanding the Challenges for Transforming Organizations", In: Proceedings of the $38^{\text {th }}$ International Conference on Information Systems (ICIS), 2017, pp. 1-21.

[62] J. Anke, "Design-integrated financial assessment of smart services", Electronic Markets, 29(1), 2019, pp. 19-35.

[63] A. Rizk, B. Bergvall-Kåreborn, and A. Elragal, "Towards a Taxonomy for Data-Driven Digital Services", In: Proceedings of the $51^{\text {st }}$ Hawaii International Conference on System Sciences, 2018, pp. 1076-1085.

[64] S. Lenka, V. Parida, D.R. Sjödin, and J. Wincent, "Exploring the microfoundations of servitization: How individual actions overcome organizational resistance", Journal of Business Research, 88 (November), 2018, pp. 328-336.

[65] M.T. Heikkinen, T. Mainela, J. Still, and J.Tähtinen, "Roles for managing in mobile service development nets", Industrial Marketing Management, 36(7), 2007, pp.909-925.

[66] J.M. Jonas, and A. Roth, "Stakeholder integration in service innovation - an exploratory case study in the healthcare industry", International Journal of Technology Management, 73(1/2/3), 2017, pp. 91-113.

[67] S.L. Vargo, P.P. Maglio, and M.A. Akaka, "On value and value co-creation: A service systems and service logic perspective", European Management Journal, 26(3), 2008, pp. 145-152.

[68] R. Schüritz, and G. Satzger, "Patterns of Data-Infused Business Model Innovation," in IEEE 18th Conference on Business Informatics (CBI), 2016.

[69] A. Nyström, S. Leminen, M. Westerlund, and M. Kortelainen, „Actor roles and role patterns influencing innovation in living labs", Industrial Marketing Management, 43(3), 2014, pp. 483-495. 